Научная статья

УДК 327.56

DOI: 10.18101/1994-0866-2021-3-47-54

\title{
СИСТЕМНЫЙ АНАЛИЗ МЕЖДУНАРОДНОГО КОНФЛИКТА
}

\author{
(c) Цырендоржиева Дари Шойбоновна \\ доктор философских наук, профессор, \\ Бурятский государственный университет имени Доржи Банзарова \\ Россия, 670000, г. Улан-Удэ, ул. Смолина, 24a \\ dari145@mail.ru
}

\begin{abstract}
Аннотация. Международные конфликты в настоящее время являются одними из основных причин нестабильности в мировой политике. Одни конфликты разрешаются, затухают, появляются другие. Цель статьи - анализ международного конфликта как одного из типов социального конфликта. В статье использован системный метод, что позволило представить международный конфликт как социальную систему. Выявлены основные элементы социальной системы. Показано, что международный конфликт имеет те же структурные элементы, что и социальная система: субъект, человеческая деятельность и отношения, внешняя и внутренняя среда. Однако в международном конфликте главная роль отводится субъектам - участникам конфликта, которые подразделяются на основные и косвенные. В структуру международного конфликта включены объект и предмет конфликта. Сделан вывод, что международный конфликт является открытой, развивающейся социальной системой.

Ключевые слова: международный конфликт, социальная система, структура, субъект, объект и предмет конфликта, человеческая деятельность, отношения, среда.
\end{abstract}

\section{Для цитирования}

Цырендоржиева Д. Ш. Системный анализ международного конфликта // Вестник Бурятского государственного университета. Философия. 2021. Вып. 3. С. 47-54.

Самые различные социальные конфликты присутствуют на протяжении всей истории развития человечества. После окончания Второй мировой войны подсчитано, что в крупных международных конфликтах погибло приблизительно двадцать миллионов человек. В эти международные конфликты были вовлечены свыше ста государств. На смену национально-освободительным войнам пришли новые, более опасные международные конфликты. В современных международных конфликтах пересекаются интересы США, Китая, России и Евросоюза, в то же время они являются точкой пересечения, столкновения ценностей мировых религий. Следует отметить, что современные внутригосударственные конфликты могут превратиться в международные конфликты. Так, например, конфликты, возникшие в Сирии и Украине как внутренние, быстро превратились в международные конфликты.

Международный конфликт представляет собой один из типов социальных конфликтов. В основе всякого социального конфликта находится противоречие, которое может возникнуть как между отдельными людьми, так и между отдельным человеком и группой людей, также между группами людей. Конфликт, будучи социальным явлением, проявляется только в социальных системах, когда 
человек или группа людей становится источником или причиной возникновения и развития противоречия.

Социальный конфликт как социальное явление изучается различными науками, является предметом исследования психологии, социологии, политологии, философии и других наук. В середине XX в. появилась новая наука конфликтология, специально занимающаяся изучением конфликтов. Можно утверждать, что проблема социальных конфликтов является междисциплинарной. На наш взгляд, системный метод лучше всего позволяет раскрыть особенности социальных конфликтов. При системном методе мы исследуем не только элементы данного объекта, но их взаимосвязь, рассматриваем объект как целое, т. е. объект предстает как система.

В различных классификациях типов и видов систем специальная роль отводится социальным системам. В философской литературе понятие «социальная система» применяется как при характеристике общества в целом, так и при обозначении отдельных элементов общества. Социальную систему можно определить как совокупность взаимосвязанных индивидов или групп индивидов, образующих целостное единство [1]. Данное определение основывается на определении системы как комплекса взаимодействующих элементов, данном Л. фон Берталанфи [2]. По мнению В. М. Краснова, основными элементами общества как системы являются социальные субъекты, человеческая деятельность, общественные потребности и общественные отношения, а также культура [3]. В. П. Фофанов критикует классификацию основных элементов социальной системы В. М. Краснова. Он полагает, что в предложенной классификации не понятно, что является системообразующим компонентом. На взгляд Фофанова, при системном исследовании общества, прежде всего, необходимо выяснить исходный элемент социальной системы, своеобразный «атом» социальный системы, а затем через этот исходный элемент вывести системное качество общества. Для него исходным элементом является социальная деятельность, именно через эту категорию ученый считает нужным исследовать общество [4]. У. К. Уледов выделил в качестве основных элементов социальной системы те же явления общественной жизни, что и В. М. Краснов: социальные субъекты; типы деятельности людей; общественные отношения как формы деятельности и общественные потребности, на удовлетворение которых направлена деятельность, при этом исключив культуру [5]. У ученого Ю. М. Резника в качестве основных элементов социальной системы определены личность, культура и социальная организация [6].

Представители органической школы в социологии человеческий индивид рассматривали в качестве простейшего социального явления или «биологической клетки». По утверждению Питирима Сорокина, например, индивид или даже несколько индивидов не образуют общественное явление. «... из индивида можно получить только индивида, - пишет он, - и нельзя получить ни того, что называется «обществом», ни того, что носит название «общественных явлений». Робинзон, живший на уединенном острове, ни сам по себе, ни своими действиями не составит ни того, ни другого» [7, с. 138]. Для возникновения общественного явления нужно, по крайней мере, два индивида, однако только наличия этих 
индивидов будет недостаточно. П. Сорокин отмечает: «Чтобы два или большее число индивидов могли составить «общество», могли дать «общественное явление», для этого необходимо, чтобы они взаимодействовали друг с другом, обменивались взаимно акциями и реакциями» [7, с. 139-140]. Как видим, по П. Сорокину, социальные связи и отношения следует рассматривать как взаимодействие между людьми, которое является общим для всех социокультурных явлений. Поэтому, по его мнению, исследование общества нужно начинать с изучения социальных связей и отношений.

Такое же мнение выражает в своих произведениях Карл Маркс. Для него основными элементами общества стали общественные связи и складывающиеся на их основе отношения между людьми. Тем самым он противопоставил их в качестве «клеточки» обособленному индивиду. «Общество не состоит из индивидов, а выражает сумму тех связей и отношений, в которых эти индивиды находятся друг к другу» [8], - пишет К. Маркс. В другом произведении он дает следующее определение общества: «Что же такое общество, какова бы ни была его форма? Продукт взаимодействия людей» [9]. По К. Марксу и Ф. Энгельсу, основное отличие общества от животных - это производительный труд, процесс общественного производства. Именно производственная деятельность позволяет рассматривать общество как относительно самостоятельную специфическую целостную систему. Таким образом, в теориях К. Маркса и П. Сорокина в качестве «клеточки», исходного элемента общества рассматриваются общественные связи, взаимодействия, отношения. В обществе как особой специфической системе развитие и ее функционирование происходят не только на основе ее законов, но и вследствие исторически сложившихся общественных отношений.

Взаимоотношения между людьми, которые возникают в процессе их деятельности, формируют сложную и многостороннюю систему общественных отношений. Данная система определяется способом производства материальных благ. Общественные отношения - это взаимоотношения между людьми, т. е. связи и зависимости, свойственные собственно человеческому обществу. Понятие «общественные отношения» позволило представить и постигать жизнь общества как процесс. «История - не что иное, как деятельность преследующего свои цели человека» [8].

Деятельность человека и общественные отношения не существуют сами по себе, друг без друга, они находятся в сложном взаимодействии. Любое новое поколение людей при своей деятельности основывается на существующей системе общественных отношений и обусловлено этими отношениями. При этом сама существующая система общественных отношений является продуктом деятельности людей предыдущего этапа. На предыдущем этапе также деятельность людей совершается на основе наличной системы общественных отношений и т. п.

Тому или иному виду человеческой деятельности соответствуют конкретные общественные отношения, или характер деятельности способствует формированию тех или иных отношений. Если же происходят значительные изменения в сфере человеческой деятельности, то соответственные изменения происходят в сфере общественных отношений. 
Общественные отношения не только зарождены человеческой деятельностью, но они являются обязательным способом (или формой) реализации любой деятельности людей. Именно это дает сущностное представление об общественных отношениях и социальных связях. Общефилософский принцип деятельности проявляется в объяснении и обосновании единства человеческой деятельности и общественных отношений.

Таким образом, на наш взгляд, основными структурными элементами социальной системы являются люди, человеческая деятельность и общественные отношения. Общество представляет собой не совокупность отдельных людей и человеческую деятельность, но и не простой комплекс общественных отношений, а целостную систему. Все элементы общества как системы определенным образом упорядочены, взаимно обусловлены и просто не могут существовать вне данной системы. Структура современных международных конфликтов более сложная, чем структура предшествующих конфликтов. В структуру международных конфликтов быстро вовлекаются новые участники, небольшие столкновения быстро разрастаются до уровня межцивилизационного противостояния.

Международный конфликт представляет собой социальную систему, в структуре которой главная роль отводится субъектам - участникам конфликта. В первую очередь основными субъектами международных конфликтов являются государства. В тех случаях, когда государства участвуют в вооруженных конфликтах в рамках коалиций, субъектами становятся коалиции государств. Субъектами также могут выступать международные организации, исполняющие посреднические и гуманитарные функции. Есть и примеры, когда международная организация (Организация Объединенных Наций) во время войны в Корее 1950-1953 гг. стала воюющей стороной конфликта. В настоящее время происходит исчезновение различий между внутренними и международными конфликтами, поэтому субъектами конфликтов становятся политические движения, террористические организации. В конфликтах террористические организации порой становятся одной из воюющих сторон, тем самым становясь субъектом конфликта. В качестве примера можно привести операцию в Афганистане вооруженных сил США и их союзников против исламского движения «Талибан» и террористической организации «Аль-Каида» после серии террористических актов 11 сентября 2001 г. в Нью-Йорке.

Кроме основных субъектов международного конфликта можно выделить косвенных участников. Они не проявляют большой активности, но выражают одобрение и оказывают моральную и материальную помощь конфликтующим сторонам. К косвенным субъектам могут быть отнесены кроме государств и международных организаций частные лица, обладающие надлежащими профессиональными качествами и имеющие международный политический авторитет. В настоящее время наблюдается повышение роли политических партий и средств массовой информации, которые воздействуют на общественное сознание [10]. СМИ имеют значительное влияние на международные конфликты. Они могут привести к конструктивным или деструктивным последствиям. На наш взгляд, политические партии и средства массовой информации можно отнести к косвенным участникам конфликта. 
Таким образом, участники международного конфликта, которые представляют конфликтующие стороны, являются основными субъектами. Остальных участников конфликта следует отнести к косвенным субъектам. Двусторонний конфликт в современном мире довольно редкое явление. Число основных и косвенных субъектов международного конфликта может увеличиваться или уменьшаться, при этом могут меняться роли самих участников. Основной участник конфликта может стать косвенным или перейти на третью сторону.

Одним из самых известных международных конфликтов настоящего времени является сирийский конфликт, который начался с гражданской войны. Структура конфликта с его начала в 2011 г. неоднократно менялась, в том числе из-за вмешательства США, России, Ирана и Турции. С самого начала конфликта основными субъектами стали Свободная сирийская армия (ССА) и террористическая группировка «Исламское государство» (ИГ), которая стала проникать в Сирию из Ирака. США в 2014 г. стали осуществлять авианалеты на террористические формирования в Сирии, а также оказывать поддержку так называемой «умеренной оппозиции» в виде вооружения и обучения отрядов. Россия в 2015 г. включилась в конфликт по договоренности с президентом Башаром Асадом на стороне правительственных войск. В октябре 2015 г. при поддержке международной коалиции в Сирии, возглавляемой США, для борьбы с Исламским государством был образован военный альянс - сирийские демократические силы, ядро которого составили курдские отряды самообороны [11]. В настоящее время можно выделить в качестве основных участников конфликта следующие субъекты: 1) формирования, выступающие на стороне президента Башара Асада, им принадлежат Сирийская арабская армия (СAA), Национальные силы обороны $(\mathrm{HCO}) ; 2)$ антиправительственные формирования (умеренная оппозиция): сирийская национальная армия (CHA), Демократические силы Сирии (CDF); 3) террористические организации: исламское государство (ИГ), «Хайят Тахрир аш-Шам» (ХТШ). Субъектам сирийского конфликта военную помощь оказывают другие государства. Так, Россия и Иран оказывают помощь правительственным силам, на стороне оппозиции выступают Турция, Саудовская Аравия и др. Эти страны, которые вовлечены в конфликт, совершенно справедливо М. В. Казанин относит к основным участникам конфликта [12].

Значительным структурным элементом международного конфликта является деятельность субъектов, у которых имеются существенные между ними противоречия. А. Г. Здравомыслов пишет: «Конфликт - это важнейшая сторона взаимодействия людей в обществе, своего рода клеточка социального бытия. Это форма отношений между потенциальными или актуальными субъектами социального действия, мотивация которых обусловлена противостоящими ценностями и нормами, интересами и потребностями. Существенная сторона социального конфликта состоит в том, что эти субъекты действуют в рамках некоторой более широкой системы связей, которая модифицируется (укрепляется или разрушается) под воздействием конфликта» [13]. Такого же взгляда придерживается Н. В. Гришина, когда утверждает, что структурными элементами социального конфликта являются субъекты конфликта и их деятельность. Н. В. Гришина утверждает, что конфликт есть «...противоречие, возникающее между людьми 
по значимым для них аспектам взаимодействия и нарушающее их нормальное взаимодействие, а потому вызывающее со стороны участников конфликта определенные действия по разрешению возникшей проблемы в своих интересах...» [14]. Отношения конфликтующих сторон являются также структурным элементом международного конфликта. Взаимоотношения сторон конфликта определяются мотивами субъектов, обусловленными противостоящими социальными позициями, ценностями, интересами, потребностями, ресурсами, уровнем организации и т. п.

Значимыми структурными элементами международного конфликта являются объект и предмет. В качестве объекта конфликта выступают территории, ресурсы природы, власть, религиозные, этнические, идеологические интересы и др. Объектом сирийского конфликта являются не только внутренние факторы: власть, экономика, этнорелигиозные и социальные разногласия, но и внешние силы, которые поддерживают оппозиционные стороны. Предметом конфликта является именно то, что послужило причиной конфликта. В Сирии причиной конфликта послужили массовые антиправительственные выступления с требованиями демократических прав и свобод, которые быстро превратились в заявления свержения правящего режима Башара Асада. Постепенно конфликт, начавшийся как гражданская война, перерос в международный конфликт.

При исследовании объекта как системы следует изучить его взаимодействие с окружающей средой. «Для данной системы окружающая среда есть совокупность всех объектов, изменение свойств которых влияет на систему, а также тех объектов, чьи свойства меняются в результате поведения системы» [15]. В работе Р. Акоффа и Ф. Эмери дается следующее определение: «Окружение системы: множество элементов и их существенных свойств, которые не являются частями системы, но изменение в любом из них может стать причиной или продуцировать изменение в состоянии системы» [16]. Из приведенных определений видно, что понятия «среда» и «окружение» совпадают.

В природе не существуют абсолютно изолированные предметы. Любой предмет так или иначе взаимодействует с другими предметами. Предметы, которые формируют среду данной системы, оказывают различное влияние на ее функционирование. Некоторые объекты оказывают значительное влияние на систему, роль других не так заметна, а без третьих существование системы невозможно. Условия среды, без которых система не может существовать и развиваться, являются существенными, необходимыми. Так, необходимым условием существования человеческого общества является географическая среда.

На развитие конфликта оказывают влияние внешние и внутренние условия. Под внешней средой международного конфликта понимаются условия, которые приводят к социальной нестабильности общества. К ним относятся такие факторы, как экономическое положение населения, низкий уровень качества жизни, религиозные и национальные различия, традиции и т. п. Внутренняя среда - это взаимоотношения между основными субъектами конфликта. Внешняя среда может оказывать положительное влияние на внутреннюю среду, т. е. данное влияние приводит к разрешению конфликта. Однако внешняя среда может оказать и отрицательное влияние, когда напряженность возрастает, конфликт между субъ- 
ектами не утихает. Как видим, международный конфликт имеет те же структурные элементы, что и социальная система в целом: люди (субъекты), деятельность и отношения, внешняя и внутренняя среда.

Исследование международного конфликта как социальной системы предоставляет большие возможности для его управления. Знание законов развития социальных систем позволит планировать способы позитивного воздействия на конфликтующие стороны и направлять развитие конфликта.

Лuтература

1. Цырендоржиева Д. Ш. Системный метод исследования общества. Москва : Спутник ${ }^{+}$, 2002. С. 25. Текст: непосредственный.

2. L.von Bertalanffy. General System Theory // Generl Systems. 1965. Vol. 1. P.1 $=$ Л.фон Берталанфи. Общая теория систем - критический обзор // Исследования по общей теории систем. Москва : Прогресс, 1969. С. 29. Текст: непосредственный.

3. Краснов В. М. К понятию общества как социальной системы // Философские науки, 1977. № 2. С. 33. Текст: непосредственный.

4. Фофанов В. П. Социальная деятельность как система. Новосибирск: Наука. Сиб. отд., 1981. С. 299-300. Текст: непосредственный.

5. Уледов А. К. Духовная жизнь общества: проблемы методологического исследования. Москва: Мысль, 1980. С. 49. Текст: непосредственный.

6. Резник Ю. М. Введение в социальную теорию: социальная онтология. Москва: ИВ РАН, 1999. С. 98. Текст: непосредственный.

7. Сорокин П. А. Система социологии. Москва: Наука, 1993. Т. 1. С. 138; 139-140. Текст: непосредственный.

8. Маркс К., Энгельс Ф. Сочинения. Т. 46, ч. 1. Москва, 1955. С. 214. Текст: непосредственный.

9. Маркс К., Энгельс Ф. Сочинения. Т. 27. Москва, 1962. С. 402. Текст: непосредственный.

10. Черкасова В. Постмодернистская парадигма в политической теории: проблема СМИ // Мировая экономика и международные отношения. 2015. № 3. С. 114-122. Текст: непосредственный.

11. Что произошло с Сирией за десять лет войны. URL: https://www.rbc.ru/politics/15/03/2021/604753db9a794749c12f6ebe (дата обращения: 03.05.21). Текст: электронный.

12. Казанин М. В. Сирийский конфликт: оценки китайских специалистов. Москва: Институт Ближнего Востока, 2017. С. 9. Текст: непосредственный.

13. Здравомыслов А. Г. Социология конфликта: Россия на путях преодоления кризиса. Москва, 1995. С. 94. Текст: непосредственный.

14. Гришина Н. В. Психология конфликта. Санкт-Петербург, 2008. С. 20. Текст: непосредственный.

15. Холл А. Д. Определение понятия системы // Исследования по общей теории систем. Москва, 1969. С. 258. Текст: непосредственный.

16. Акофф Р., Эмери Ф. О целеустремленных системах: перевод с английского. Москва: Сов. радио, 1974. С. 27. Текст: непосредственный.

Статья поступила в редакциию 05.06.2021; одобрена после рецензирования 05.07.2021; принята к публикации 14.09.2021. 
SYSTEM ANALYSIS OF THE INTERNATIONAL CONFLICT

Dari Sh. Tsyrendorzhieva

Dr. Sci. (Philos.), Prof.,

Dorzhi Banzarov Buryat State University

24a Smolina St., Ulan-Ude 670000, Russia

dari145@mail.ru

Abstract. International conflicts are currently one of the key reasons for instability in world policy. Some conflicts are resolved, fade out, others appear. In the article we have analyzed the international conflict as one of the types of social conflict, using a systemic method, which made it possible to present the international conflict as a social system. We have revealed the main elements of the social system. It is shown that the international conflict has the same structural elements as the social system: the subject, human activity and relations, external and internal environment. However, the major role in the international conflict is assigned to the subjects/participants in the conflict, which are divided into direct and indirect ones. The object and subject of the conflict are included in the structure of the international conflict. It is concluded that the international conflict is an open, developing social system.

Keywords: international conflict, social system, structure, subject, object and subject of conflict, human activity, relations, environment

\section{For citation}

Tsyrendorzhieva D. Sh. System Analysis of the International Conflict. Bulletin of Buryat State University. Philosophy. 2021; 3: 47-54 (In Russ.).

The article was submitted 05.06.2021; approved after reviewing 05.07.2021; accepted for publication 14.09.2021. 